\title{
The effect of mindfulness-based stress reduction on the test anxiety of Students at the University of Garmian
}

\author{
Pegah Ali-Mardan Seidi ${ }^{{ }^{*}}$ Abubakr Yusif Ahmad ${ }^{2}$
}

${ }^{1}$ Department of Psychology, College of Education, University of Garmian, Kurdistan Region, Iraq

${ }^{2}$ Department of Psychology, College of Education, University of Garmian, Kurdistan Region, Iraq Email: Abubakr.Yusif@garmian.edu.krd

*Corresponding author. Email: Pegah.am.seidi@garmian.edu.krd

\begin{abstract}
This study aimed to investigate the effect of mindfulness-based stress reduction on reducing of test anxiety in students. The research method was Quasi experimental with pretest-posttest and control groups. The statistical population consisted of all students at the University of Garmian in the 2017-2018 academic years. Sample was selected among them by using the result of Spielberger's Test Anxiety, 30 students who had high scores on test anxiety (one standard deviation above the mean group), were selected and randomly assigned in two experimental and control group. Experimental groups, received 8 sessions of mindfulness-based stress reduction program. For collecting data Spielberger's Test Anxiety was used. The data were analyzed by ANCOVA statistical method. The results showed that there are significant differences between the experimental and control groups. Mindfulness-based stress reduction was influential in reducing test anxiety in students. There was also significant difference between the two groups considering the gender, that in girls, mindfulness-based stress reduction program in comparison with the boys was more effective in reducing test anxiety of students. Therefore, the research hypothesis was approved. So we can conclude that training of mindfulness-based stress reduction is effective in reducing test anxiety especially in girls.
\end{abstract}

Keywords: Mindfulness, Mindfulness-based stress reduction, Test anxiety, students.

\section{Introduction}

Given that the present era is the age of competition in different areas, academic achievement is one of the predictors of success. Therefore, factors which affect the individual's academic performance have been in the vogue, and test anxiety is one of these factors. Anxiety is generally a psychological state experienced on four dimensions. On the cognitive dimension, expecting an unpleasant incident, physically, causes 
biochemical changes in the brain and the body (such as increasing adrenaline or decreasing dopamine). The emotional excitement of anxiety causes anxiety, fear, and anger, and ultimately behavioral acts lead to an escape or confrontation (Sadock and Sadock, 2001). Sarason examines test anxiety as a form of self-employment, which is characterized by self-doubt and doubt about his/her abilities and often leads to negative cognitive assessment, distraction, adverse physiological reactions, and failure of individual in academic performance (Sarason and Sarason, 2009).

Although low level of anxiety is a trigger to improve academic performance, the higher levels disturb attention and concentration, memorization and retrieval which ultimately lead to the academic failure. Since test anxiety affects many learners in each academic year, despite the rich literature in this regard, particular studies of test anxiety treatment are still ongoing (Lebeau et al., 2010). Previously, test anxiety was not identified as a specific disorder in Diagnostic and Statistical Manual of Mental Disorders, but it was classified as a distinct form of social phobia. In the latest edition of this manual, it is also considered as a disabling and widespread disrupting situation. Its classification in the diagnostic group of social phobia makes it easier to diagnose and treat (American Psychiatrist Association, 2013).

In recent years, therapies called the Third Wave of Cognitive-Behavioral Therapy have been significantly successful, especially in the treatment of anxiety and behavioral disorders. One of these treatments is the use of mindfulness techniques. Research on this widespread disorder has continued since 1996, due to the significant effects of mindfulness on the reduction of physical and psychological disabilities (Saltzman, 2014).

Kabat Zin, who was the first to use the psychological intervention for mindfulness, defines it as follows: "Attention without judgment and momentarily to the inner and outer stimuli" (Kabat Zinn, 2003). The main purpose of mindfulness is to be the alert and to steadily observe changes in the inner and outer stimuli (Bear, 2003). The most common approach is mindfulness-based stress reduction (MBSR) which is known as a program for reducing stress and learning relaxation.

Research supports that mindfulness interventions, especially the MBSR program, can positively affect such diverse components as assertiveness, general anxiety, and test anxiety. Volcumer (2015) in a meta-analysis investigated the effectiveness of mindfulness interventions on different forms of anxiety and reported that these interventions, as a whole, were effective in diminishing anxiety. Gallego et al., (2015) 
found that mind-boggling exercises and training in physiological knowledge of the body helped reduce students' anxiety and stress for an exam. In a study, titled Comparing the Effectiveness of a Mindfulness-Based Program with Study Skills in the Treatment of Student's Test Anxiety, Paterniti (2007) concluded that both methods effectively reduced test anxiety but mindfulness awareness interventions were more effective. In another study titled "The Effect of Cognitive-Based Mindfulness on Students Anxiety", Ferrando (2005) found that this intervention reduced adolescent anxiety in students.

The effectiveness of these interventions on students' test anxiety is attested, but there is no similar research on students of the Kurdistan Region of Iraq. Thus, this study aims to investigate the effectiveness of mindfulness-based stress reduction on test anxiety among students of University of Gramian.

\section{Material and Methods}

This is a quasi-experimental study with a pre-test/post-test design and control groups. In this research design, participants are not randomly selected, but they are randomly assigned to two experimental and control groups. Before applying the independent variable on the experimental group, both groups are assessed with a pre-test. Then, the experimental group receives the intervention while the control group receives no treatment. Both groups are re-evaluated with a post-test. Table 1 demonstrates the research design

Table 1: Diagram of the research design

\begin{tabular}{|l|l|l|l|l|}
\hline $\begin{array}{l}\text { Randomly } \\
\text { assigning }\end{array}$ & Post-test & $\begin{array}{l}\text { Independent } \\
\text { variable }\end{array}$ & Pre-test & Groups \\
\hline E & $\begin{array}{l}\text { Spillberger's test } \\
\text { Anxiety Inventory } \\
\text { (STAI) }\end{array}$ & $\begin{array}{l}\text { MBSR } \\
\text { Intervention }\end{array}$ & $\begin{array}{l}\text { Spillberger's test } \\
\text { Anxiety Inventory } \\
\text { (STAI) }\end{array}$ & Experimental \\
\hline C & $\begin{array}{l}\text { Spillberger's Test } \\
\text { Anxiety Inventory } \\
\text { (STAI) }\end{array}$ & & $\begin{array}{l}\text { Spillberger's Test } \\
\text { Anxiety Inventory } \\
\text { (STAI) }\end{array}$ & Control \\
\hline
\end{tabular}


The population of this study included all undergraduate students at the University of Garmian in the academic year 2017-2018. As a sample, 150 students were selected. They took the test anxiety questionnaire, and from the students who scored high on the test anxiety questionnaire (a standard deviation higher than the mean of the group) 30 students were randomly selected and divided into the experimental and control groups. The following tools were used to collect the data:

Spillberger's Test Anxiety Inventory: This questionnaire, developed by Spillberger (1980), contains 20 multiple-choice items (never, sometimes, often, and always). The minimum score on the questionnaire is 20 and the maximum is 80 . A high score on this questionnaire indicates a high test anxiety. Research proves that the validity and reliability of the questionnaire are acceptable. The correlation values between this questionnaire and Sarason's test anxiety scale and Stoops' (1978) in boys and girls are 82.0 and 83.0, respectively. The correlation of this questionnaire with the state-trait anxiety questionnaire in boys and girls are reported as 86.0 and 77.0 respectively. Cronbach's alpha coefficient of this questionnaire is higher than 92.0 in male and female samples. The retest reliability coefficients of this questionnaire are reported after 40.0 and 70.0 weeks (Register et al., 1991).

As this questionnaire was not translated into Kurdish, consequently a team of experts at Garmian University translated it into Kurdish. Then, to make sure of its face validity, we presented the title and goals of the study along with the Kurdish version of the questionnaire to a group of five psychology professors at Garmian University. After their approval, the final version of the questionnaire was prepared. A sample consisting of 50 students participated to investigate its validity and reliability. Cronbach's Alpha was used to calculate its reliability, and a correlation coefficient of 0.73 was obtained. As a whole, the results approved the reliability and validity of final Kurdish version of the questionnaire

After sampling, the participants in the experimental group were informed about the underlying mindfulness based stress reduction program and the control group did not receive any training and continued their normal routine. Training session is summarized in Table 2. 
Table 2: Summary of mindfulness based stress reduction training

\begin{tabular}{|c|c|}
\hline Sessions & Intervention Content \\
\hline 1 & $\begin{array}{l}\text { Establishing communication, defining and conceptualizing, as well as emphasizing the } \\
\text { need for mindfulness training. }\end{array}$ \\
\hline 2 & $\begin{array}{l}\text { Familiarizing with relaxation, training relaxation for } 14 \text { groups of muscles including } \\
\text { forearm, arm, muscle behind the leg, thighs, abdomen, chest, shoulders, neck, lips, eyes, } \\
\text { jaws and forehead. }\end{array}$ \\
\hline 3 & $\begin{array}{l}\text { Training relaxation for } 6 \text { groups of muscles including hands and arms, legs and thighs, } \\
\text { abdominal and chest, neck and shoulders, jaws, forehead and lips and assigning } \\
\text { homework. }\end{array}$ \\
\hline 4 & $\begin{array}{l}\text { Training respiratory mindfulness, a brief review of the previous sessions, understanding } \\
\text { how to breathe in mind, teaching the technique of the tailing and exhilarating with } \\
\text { relaxation and without thinking about anything else, teaching the technique of } \\
\text { monitored breathing and training for breathing mindfully for } 20 \text { minutes before going to } \\
\text { sleep. }\end{array}$ \\
\hline 5 & $\begin{array}{l}\text { Teaching body scanning technique: instructing how to pay attention to body movements } \\
\text { during breathing, focusing on the organs of the body and their movements, and } \\
\text { searching for physical senses (hearing, taste, etc.). Assigning mindful eating as a } \\
\text { homework (eating calmly and paying attention to the taste of the food) }\end{array}$ \\
\hline 6 & $\begin{array}{l}\text { Thinking mindfully: thinking about mind, negative and positive thoughts, pleasant and } \\
\text { unpleasant thoughts, allowing negative and positive thoughts to enter the mind, and } \\
\text { easily removing them from the mind without judgment and deep attention to them, } \\
\text { jotting down negative and positive daily sensations without judgment. }\end{array}$ \\
\hline 7 & Complete Mindfulness: repeating sessions 4, 5 and 6 each for $20-30$ minutes \\
\hline 8 & Reviewing and summarizing previous sessions and taking the post-test. \\
\hline
\end{tabular}

\section{Results}

The mean and standard deviation of the pre-test and post-test anxiety tests in both the experimental and control groups are presented in Table 3.

Table 3: Mean and standard deviation of test-anxiety scores obtained by the experimental and control groups on the pre-test and post-test

\begin{tabular}{|l|l|l|l|l|l|l|l|}
\hline \multicolumn{2}{|c|}{ Groups } & \multicolumn{2}{l}{ Pre-test } & \multicolumn{2}{l|}{ Post-test } \\
\cline { 3 - 9 } \multicolumn{2}{c|}{} & N & Mean & SD & N & Mean & SD \\
\hline \multirow{3}{*}{ Test anxiety } & Experimental & 15 & 58.13 & 2.80 & 15 & 51.47 & 3.02 \\
\cline { 2 - 9 } & Control & 15 & 58.47 & 2.72 & 15 & 57.93 & 1.90 \\
\cline { 2 - 8 } & Total & 30 & 58.30 & 2.71 & 30 & 54.70 & 4.12 \\
\hline
\end{tabular}


In the present study, the pre-test score was recognized as a synchronous variable; consequently after examining the necessary assumptions, a covariance analysis was performed to determine the effect of the pre-test on the post-test scores. The results of the Levine test confirmed the assumption of homogeneity of variances $(p=0.246>$ 0.05). In addition, the data analysis using Klomograph-Smirnov test group also confirmed the normal distribution of data. The data were analyzed using a covariance analysis, the results of which are reported in Table 4.

Table 4: Results of Analysis of Covariance to compare post-test scores

\begin{tabular}{|l|r|r|r|r|r|r|}
\hline Source & \multicolumn{1}{|c|}{$\begin{array}{l}\text { Type III } \\
\text { Sum of } \\
\text { Squares }\end{array}$} & \multicolumn{1}{|c|}{ df } & \multicolumn{1}{c|}{$\begin{array}{c}\text { Mean } \\
\text { Square }\end{array}$} & F & \multicolumn{1}{c|}{ Sig. } & \multicolumn{1}{c|}{$\begin{array}{c}\text { Partial Eta } \\
\text { Squared }\end{array}$} \\
\hline pretest & 92.519 & 1 & 92.519 & 28.997 & .000 & .518 \\
\hline Groups & 291.570 & 1 & 291.570 & 91.382 & .000 & .772 \\
\hline Error & 86.148 & 27 & 3.191 & & & \\
\hline
\end{tabular}

As shown in table 4, the result of the covariance analysis suggests that there is a significant difference between the post-test scores of these two groups, while the effect of the pre-test is controlled $(\mathrm{P}=0.013, \mathrm{P}=91.38)$. That is, based on the average scores, there is a difference between groups in test anxiety (the dependent variable). According to the obtained coefficient, $77 \%$ of the observed differences are due to mindfulness interventions.

Independent t-test was used to assess the differences between the sexes in the effectiveness of the intervention and the results of this analysis showed that although girls had higher scores in test anxiety than boys, there was no significant difference in the effectiveness of this intervention on their anxiety. These analysis results are presented in Table 5.

Table 5: T-test results for comparison between male and female students

\begin{tabular}{|l|l|l|l|l|l|l|}
\hline \multicolumn{2}{|c|}{} & \multicolumn{2}{l|}{$\begin{array}{l}\text { Levene's Test for Equality of } \\
\text { Variances }\end{array}$} & \multicolumn{3}{l|}{ t-test for Equality of Means } \\
\cline { 3 - 7 } \multicolumn{2}{|c|}{} & F & sig & t & df & Sig. \\
\hline $\begin{array}{l}\text { Post- } \\
\text { test }\end{array}$ & $\begin{array}{l}\text { Equal variances } \\
\text { assumed }\end{array}$ & .001 & .978 & 1.222 & 28 & .232 \\
\cline { 2 - 7 } & $\begin{array}{l}\text { Equal variances } \\
\text { not assumed }\end{array}$ & & & 1.214 & 23.181 & .237 \\
\hline
\end{tabular}




\section{Discussion}

The purpose of this study was to investigate the effectiveness of mindfulness interventions, based on stress reduction. In order to determine the effectiveness of this study among the students of Garmian University, 30 participants who scored higher on the Spielberger test for anxiety test were selected and randomly assigned to the intervention and control groups. The experimental group was trained for 8 weeks of mindfulness-based stress reduction, but the control group did not receive any intervention.

The findings showed that there was a significant difference between the experimental and control groups. That is, the training program of mindfulness-based stress reduction was effective in reducing test anxiety. Therefore, the research hypothesis was confirmed . This finding is consistent with previous studies, e.g. Shahidi and et al., (2017); Dundas and et al., (2016); Song, Lindquist (2015); Paterniti (2007) and Beauchemin (2008).

Mindfulness techniques are effective in reducing muscle tensions, worries, and consequently, in reducing anxiety and stress (Kabat Zeinn, 2003). It seems that the main mechanism of mindfulness is self-control attention, because the repeated concentration on a neutral stimulus, such as breathing, creates a meaningful environment. It also discards the threatening thoughts and worries about performance during the exams and assessments (Sample et al., 2005).

Preliminary data show that mindfulness training may be a good alternative to the conventional psychological treatment of anxiety disorders- especially for those who do not want to attend traditional treatment sessions or those who do not respond to the treatment (Miller, Fletcher and Kabat-Zein, 1995).

Mindfulness, in addition to control of anxiety, enables the person to attentively study and investigate all dimensions with full awareness. This situation leads to the semantic extension and better organization of the content and achieving a better cognitive organization of the subject. This more cohesive cognitive organization leads to better retrieval of the information. The best method to treat test anxiety is intervention that includes such components as psychological training about test anxiety, control of attention, spontaneity, and self-control (Paterniti, 2007). 
In mindfulness method, mental and physical aspects will be considered simultaneously to control and manage the emotions. The person is taught to be fully aware of his thoughts and feelings, to accept them without judgment, and to look at the matters more positively. In addition to full knowledge of thoughts and feelings and their acceptance without judgment, a person who is in a state of tranquility and concentration is able to control his/her thoughts, anxieties, and emotions. These capabilities make the person feel more in control of all aspects of his life. Negative automatic responses are discarded in stressful situations, and people can respond with greater control, calmness, and awareness, and deal beter with problems (Kabat-Zainn, 1990).

According to the findings, it is recommended that mindfulness-based stress reduction program methods to be used to reduce test anxiety. One of the limitations of this study was the lack of follow-up study of intervention effects which was inevitable due to time and financial constraints. Therefore, follow-up studies are recommended. The authors would like to thank all the students at the University of Garmian who helped us with this research.

\section{References}

American Psychiatrist Association (2013). The Diagnostic and Statistical Manual of Mental Disorders, Fifth Edition.

Baer, R. A. (2006). Mindfulness-based treatment approaches: Clinicians guide to evidence base and application. USA: Academic Press is an Imprint of Elsevier.

Beauchemin, J., Hutchins, T. L., \& Patterson, F. (2008). Mindfulness meditation may lesson anxiety, promote social skills, and improve academic performance among adolescents with learning disabilities. Complementary Health Practice Review, 13, $34-45$.

Burke, A., \& Koopman, C. (2004). The effects of a mindfulness-based stress reduction program on stress, mindfulness self-effi-cacy, and positive states of mind. Stress and Health, 20, 141-147.

Chang, V. Y., Palesh, O., Caldwell, R., Glasgow, N., Abramson, M., Luskin, F., Gill, M., Dundas I, Thorsheim T, Hjeltnes A, Binder P.E. (2016). Mindfulness Based Stress Reduction for Academic Evaluation Anxiety: A Naturalistic Longitudinal Study. J College Stud Psychother. 2016 Apr 2; 30(2): 114-131. 
Ferrando, S. (2005). Mindfulness-based cognitive therapy for trait anxiety. Journal of Psycho, 22, 1-12.

Gallego J, Aguilar-Parrra JM, Cangas AJ, Lander AI, Manas I. (2015). Effect pf mindfulness program on stress anxiety and depression in university students. Span J Psychol. 17: E109.

Grossman, P., Niemann, L., Schmidt, S., \& Walach, H. (2004). Mindfulness-based stress reduction and health benefits: a meta-analysis. Journal of Psychosomatic Research, $57,35-43$.

Kabat-Zin J. (2003). Mindfulness- Based intervention in contex: past, present, and future. Clinical Psychology: Science and Practice . 10; 144-56.

Kabat-Zinn, J. (1990). Full catastrophe living: using the wisdom of your body and mind to face stress, pain and illness. New York: Delacorte.

Kristeller, J. L. (2007). MIndfulness Meditation. In P. Lehrer, R.L. Woolfolk \& W.E. Sime (Eds.), Principles and practice of Stress Management (3rd ed.). New York: Guilford.

Kristeller, J. L. (2007). MIndfulness Meditation. In P. Lehrer, R.L. Woolfolk \& W.E. Sime (Eds.), Principles and practice of Stress Management (3rd ed.). New York: Guilford.

LeBeau RT, Glenn D, Liao B, Wittchen H-U, Beesdo-Baum K, Ollendick T, et al. (2010). Specific Phobia: a review of DSM-IV specific phobia and preliminary recommendation for DSM-V. Depress Anxiety. 27(2): 148-167.

Miller, J. J., Fletcher, K., \& Kabat-Zinn, J. (1995). Three-year follow-up and clinical implications of a mindfulness meditation-based stress reduction intervention in the treatment of anxiety disorders. General Hospital Psychiatry, 17, 192-200.

Paterniti, A. (2007). Comparing the efficacy of a mindfulness-based program to a skillstraining program in the treatment of test anxiety. Unpublished Doctoral Dissertation, Island, England: University of Islan.

Register A.C. Beckham DJ, May JG, \& Gustafson DJ. (1991) stress inoculation bibliotherapy in the treatment of test anxiety. Journal of Counseling Psychology. 38(2): $115-116$ 
Sadock, B.J. and Sadock, V.A. (2003) Kaplan and Sadock's Comprehensive Textbook of Psychiatry. 7th Edition, Lippincott, Williams and Wilkins, Philadelphia.

Saltzman A. (2014). A still quiet place: a mindfulness program for teaching children and adolescents to ease stree and difficult emotions. Ookland: New Harbinger Publication

Santorelli, S. F., \& Kabat-Zinn, J. (2002). Mindfulness-based stress reduction Professional training resource manual. Worcester, MA: University of Massachusetts Medical School.

Santorelli, S. F., \& Kabat-Zinn, J. (2002). Mindfulness-based stress reduction Professional training resource manual. Worcester, MA: University of Massachusetts Medical School.

Sarason IG, Sarason BB(2009). Test anxiety. In leitenberg H. Handbook of social and evaluative anxiety. New York: Plenum Press.

Semple, R. J., Reid, E. F. G., \& Miller, L. (2005). Treating anxiety with mindfulness: an open trial of mindfulness training in anxious children. Journal of Cognitive Psychotherapy: An International Quarterly, 19, 379-392.

Shahidi SH, Akbari H, and Zargar F. (2017). Effectiveness of mindfulness-based stress reduction on emotion regulation and test anxiety in female high school students. J Educ Health Promot. 2017; 6: 87.

Shapiro, S. L., Astin, J.A., Bishop, S. R., \& Cordova, M. (2005). Mindfulness-based stress reduction for health care professionals: results from a randomized trial. International. Journal of Stress Management, 12, 164-176.

Song Y1, Lindquist R2.(2015). Effects of mindfulness-based stress reduction on depression, anxiety, stress and mindfulness in Korean nursing students. Nurse Educ Today. 2015 Jan;35(1):86-90. 